\title{
Nurse Educators' Perceptions of Ecoliteracy in Undergraduate Nursing Education
}

Jennifer L. Morin

Red River Community College, jlmorin@rrc.ca

Benita Cohen

University of Manitoba, Benita.Cohen@umanitoba.ca

Nicole Harder

University of Manitoba, nicole.harder@umanitoba.ca

Shirley Thompson

University of Manitoba, s.thompson@umanitoba.ca

Follow this and additional works at: https://qane-afı.casn.ca/journal

Part of the Community Health and Preventive Medicine Commons, Environmental Public Health Commons, Occupational and Environmental Health Nursing Commons, Other Nursing Commons, and the Public Health and Community Nursing Commons

\section{Recommended Citation}

Morin, Jennifer L.; Cohen, Benita; Harder, Nicole; and Thompson, Shirley (2022) "Nurse Educators' Perceptions of Ecoliteracy in Undergraduate Nursing Education," Quality Advancement in Nursing Education - Avancées en formation infirmière: Vol. 8: Iss. 1, Article 5.

DOI: https://doi.org/10.17483/2368-6669.1287

This Article is brought to you for free and open access by Quality Advancement in Nursing Education - Avancées en formation infirmière. It has been accepted for inclusion in Quality Advancement in Nursing Education - Avancées en formation infirmière by an authorized editor of Quality Advancement in Nursing Education - Avancées en formation infirmière. 


\section{Introduction}

The relationship between the natural environment and human health is a complex and vital area of study. In particular, the impact of climate change on the natural environment and human health has garnered increasing attention in recent years. Climate change is thought to be "the greatest health threat of the 21 st century," and although climate change can occur naturally, human activity, primarily "the burning of fossil fuels and deforestation[,] result in the release of carbon dioxide into the environment that [causes] a greenhouse effect....Changes in temperature, increases in extreme weather events, changes in patterns of vector driven infectious disease, polar ice decline, sea level rise, and changes in plant food production" are linked to climate change (Canadian Public Health Association [CPHA], 2019, Context section).

Environmental pollution linked to climate change through fossil fuel combustion causes three times more deaths than AIDS, tuberculosis, and malaria combined (Landrigan et al., 2018), and it worsens many diseases, including outcomes for COVID-19 (Setti et al., 2020). In Canada, wildfires have exposed affected populations to levels of air pollution rated as "high risk" and "very high risk" (CPHA, p. 8), and the number and extent of these wildfires increase globally through climate change causing extreme heat and drought. The Lancet Countdown (Watts et al., 2018) concluded, "The human symptoms of climate change are unequivocal and potentially irreversible — affecting the health of populations around the world today" (p. 581).

Nurses are essential in responding to the health impacts of climate change. Through mitigation and adaptation strategies, nurses play a key role in improving the resiliency of individuals and communities in Canada. Nurse's roles are vast, ranging from providing direct patient care, education, and health promotion interventions to being trusted respondents during all phases of disaster response. Additionally, nurses are environmental health stewards and should be involved in reducing the health sector's impact on ecological degradation (Lopez-Medina et al., 2019).

Ecoliteracy is defined as an understanding of the relationship between ecosystem health and human health. Ecoliteracy focuses on promoting an eco-centric professional (Goleman et al., 2012), a professional who considers environmental factors that impact health, integrates concepts of sustainability, and advocates for environmental justice (Canadian Nurses Association [CNA], 2017a). Organizations such as the Canadian Association of Schools of Nursing (2021) have identified the need for the next generation of health care professionals to be literate in the areas of climate change in Canada and the impact it has on the health of Canadians; however, this is still an emerging area in nursing education. In nursing education, the area of interest involves what is required to further understand the complex relationship between environmental health and human health and to enable future professionals to address complex ecological concerns within the nursing scope of practice. This paper considers the concept of ecoliteracy within nursing education to understand what is required to be ecoliterate and competent in our changing environment.

\section{Background}

To anticipate and adequately care for the needs of individuals and communities affected by climate change, nurses and other health care providers need a strong understanding of the interrelationship between climate change, the natural environment, and human health (International Council of Nurses [ICN], 2018; Leffers et al., 2017; Sullivan-Marx \& McCauley, 2017). This process requires appropriate preparation in environmental health. Although a nurse's role in addressing environmental change is well articulated in the government and professional 
association statements below, further development of competencies to guide curriculum development is needed (Leffers, et al., 2017). Nurses' perceptions of their role in the practice setting to address climate change are not well understood (Iira et al., 2020).

\section{Professional and Regulatory Bodies}

The CNA Code of Ethics (2017b) is a document that is both aspirational and regulatory. It reflects changes currently affecting nurses and nursing students and is used by nurses in ethical decision-making. The Code of Ethics states that nurses are expected to maintain awareness of global health concerns, including environmental change, and support environmental preservation and restoration while advocating for initiatives that reduce environmentally harmful practices. The Code of Ethics is integrated in nursing curricula throughout Canada; however, the extent likely varies.

Standards of practice are necessary to define the scope of nursing practice; establish criteria; determine acceptable nursing practice; benchmark safe, ethical care; and set standards for measuring performance (Community Health Nurses of Canada [CHNC], 2019). These standards, as well as entry-level nursing competencies, provide educators with a framework to design prelicensure nursing education curricula. Position statements indicate the perceived importance of an issue and the need to address it, and often statements will include recommendations. Examples of these types of professional nursing practice expectations at international, national, and (in Canada) provincial and territorial levels are described below.

\section{International Recommendations for Practice}

The ICN (2018) published a position statement that strongly supports nurses' involvement in addressing various environmental health issues. Nurses, Climate Change and Health acknowledged the vital contribution nurses can make in supporting people and communities in mitigating and adapting to climate change. Recognizing the complex relationship between climate change and health, the ICN predicted an increased demand for well-educated and prepared nurses with the knowledge and skills set required to care for people/communities with health concerns attributed to climate change. Meeting the predicted demand for well-prepared nurses to address the health impacts of climate change might prove difficult. Leffers et al. (2017) identified resistance to include climate curriculum in nursing programs. A lack of engagement and limited knowledge among nurse leaders challenge the implementation of climate change competencies into nursing programs.

\section{Canadian Recommendations and Standards for Practice}

CNA $(2017 \mathrm{a}, 2017 \mathrm{c})$ provides position statements on climate change and environmental health that call for an ecoliterate nursing workforce. Nurses and Environmental Health (CNA, 2017a) outlined several critical nursing roles in environmental health, including assessment of hazards, education, leadership in reducing harm to the environment, collaboration to mitigate risk, advocacy for policies to promote sustainability, and research. Additionally, the Canadian Federation of Nurses Unions (2019) supports nurses' roles in addressing climate change in practice, urging nurses to green their workplace, to increase their knowledge of climate change science, to advocate for provincial or territorial and federal actions to reduce greenhouse gas emissions, and to increase their understanding of adaptation and mitigation strategies to improve individual and health sector resiliency in the face of climate change. 
The 2019 Canadian Community Health Nursing Professional Practice Model and Standards of Practice (CHNC, 2019) stated that the community health nurse applies health promotion theories and models in practice, including those related to the ecological determinants of health. Further, CHNC (2019) stated that the community health nurse, when appropriate, will incorporate Indigenous ways of knowing, including "connectedness and reciprocity to the land" (p. 14). Leffers et al. (2017) supported the need for clear, culturally appropriate learning objectives that guide curriculum development, though they recommend that climate education be expanded beyond the practice of community and public health nurses to reach all nurses in all practice settings.

\section{Provincial/Territorial Entry-Level Competencies}

The College of Registered Nurses of Manitoba (2019) included the following statement in its entry-to-practice requirements under the advocacy domain: "supports environmentally responsible practice" (p. 7). Similar entry-level competencies that focus on environmentally responsible practice can be found in other Canadian jurisdictions (see, for example, College and Association of Registered Nurses of Alberta, 2019; College of Nurses of Ontario, 2020). There is an increasing need for nursing curricula to move beyond a focus on sustainability content; what is required is a greater emphasis on adaptation and resiliency strategies (Iira et al., 2020; Leffers et al., 2017).

\section{The Research-to-Practice Gap}

There is a strong body of literature focused on health concerns relating to climate change and calls for the preparation of nurses in environmental health (Leffers \& Butterfield, 2018; Leffers et al., 2017; Nicholas \& Breakey, 2017; Sullivan-Marx \& McCauley, 2017). Analysis of the literature indicates that nurses' lack of environmental health preparation is a barrier to incorporating environmental health concepts into practice (Jackman-Murphy, 2015; Leffers et al., 2017) and inhibits their ability to consider the natural environment as a determinant of health. Furthermore, Kalogirou et al. (2020) posited that although the nursing metaparadigm (person, health, nurse, environment) has evolved over the years and nursing grand theorists have expanded on the conceptualization of the "environment," the focus of "environment" remains on the individual rather than on society. It can be inferred that because of the historical conceptualizations of "environment," nurses have a difficult time understanding their professional role in addressing climate change.

Although the literature speaks to the need for an ecoliterate nursing workforce, little to no empirical evidence exists about Canadian nurse educators' perceptions of ecoliteracy in undergraduate nursing programs.

\section{Research Objectives}

The objectives of this study were to explore nurse educators' perceptions of ecoliteracy within undergraduate nursing education in one Canadian Prairie province related to (a) their understanding of the concept of ecoliteracy and its relevance to nursing practice, (b) their perceptions about how ecoliteracy concepts are currently delivered and evaluated in undergraduate nursing programs, and (c) their perceptions about the barriers and facilitators to the inclusion of content that supports ecoliteracy in undergraduate nursing curricula. 


\section{Methods}

\section{Study Design and Participants}

A descriptive qualitative research design was used to explore nurse educators' perceptions about ecoliteracy in undergraduate nursing curricula. Descriptive qualitative research has been identified as important and appropriate for improving understanding a poorly understood nursing phenomenon and providing a summary of individuals' perceptions of events (Kim et al., 2017; Neergaard et al., 2009). This study is a first step in understanding the perspectives of nurse educators on ecoliteracy within undergraduate nursing education programs. The population health promotion model and the population health framework were used loosely to guide the research, as the definition of environment in each was limiting, failing to address the complexity of the topic in its entirety. Neither of the two frameworks used the proactive ecosystem sustainability language of the Ottawa Charter, although both recognize the physical and built environment as a determinant of health.

A systematic review conducted by Kim et al. (2017) recognized that researchers using a qualitative descriptive approach "may or may not decide to begin with a theory of the targeted phenomenon and need not stay committed to a theory or framework if their investigations take them down another path" (p. 23). Further, Sandelowski (2000) argued that not being committed to a theory does not mean not being influenced by a theory. This was the lens through which the current study was conducted.

Scholars suggest that purposeful sampling is the appropriate sampling approach for qualitative descriptive research. Simply put, purposeful sampling deliberately selects specific individuals or groups to study based on those thought to be most informative (Polit \& Beck, 2020). Since the objective was to learn directly from nurse educators regarding their perspective of ecoliteracy in nursing education, we recruited from academic institutions where nurse educators are employed using specified inclusion criteria. Two levels of purposeful sampling and sample variation were used for sample selection: (a) selection of three university undergraduate nursing programs from three different geographic regions of one Canadian Prairie province: large urban, small urban, and northern; and (b) selection of individual participants at each study site. The three geographically unique study sites were chosen to see whether scale and geography resulted in differences in educators' perceptions of ecoliteracy and the role for environmental health education.

Limited recruitment required broadening the original eligibility criteria. The revised inclusion criteria for faculty members included holding an academic appointment for a minimum of one year and current or past teaching experience with the following environmental or ecosystem health-oriented courses: community or population health, health promotion/prevention of illness, maternal child and pediatric health, health assessment, medical/surgical nursing, or leadership/management/advocacy.

\section{Data Collection}

Following the University of Manitoba Research Ethics Board approval in spring 2016, a request for access to faculty members was made to the deans and directors of undergraduate nursing programs in the three geographically unique academic sites. After access was granted, letters of invitation were distributed to faculty indirectly at two sites (via the dean's office and research office) and directly by the first author at another site. Interested participants who were 
eligible contacted the first author to complete the informed consent process. Interviews, conducted by the first author via telephone, consisted of semi-structured interview questions and typically lasted about one hour. The telephone interviews were audio-recorded and transcribed verbatim. Data collection ended December 2016.

\section{Data Analysis}

This study used qualitative content analysis, an analytic approach that is not linked to a research tradition, which is the process of organizing data and integrating material from documents, including transcripts and field notes from a qualitative study, according to key themes and patterns (Polit \& Beck, 2020). In this method of analysis, the researcher familiarized herself with the data, before breaking them down into smaller meaning units, which were then labelled with a code (Graneheim \& Lundman, 2004). Meaning units as defined by Graneheim and Lundman (2004) are smaller units that contain some of the insights the researcher needs to answer the research questions. Content analysis is useful in analyzing interviews because it involves aggregating identical codes within a concept and organizing them into categories and themes that can be understood by the readers (Graneheim \& Lundman, 2004).

The researchers used Microsoft Word to analyze data. An initial review of a sample of transcripts from each academic site was completed. The first researcher read each transcript once to acquire a sense of the concepts and to ensure that the transcript was clear, then a second time to begin forming codes to group similar data. In this case, initial coding was carried out by following the interview question guide, reflective of the research objectives. From these codes, themes arose and a general sense of what the data were reflecting could be inferred. After potential themes were established and areas for further analysis were identified, the researcher further immersed herself in the data to establish an understanding of the participants' experiences. This process of finding meaning in the underlying concepts during data analysis is referred to as latent content analysis (Polit \& Beck, 2020). The themes identified were then translated into thematic sentences, which are a means of summary that have the ability to preserve the intricate nature of each participants' experience with the phenomenon (Sandelowski \& Leeman, 2012). Similar to what Polit and Beck (2020), referred to as manifest content, this method of qualitative content analysis is subject to little interpretation by the researcher. The goal of data analysis in qualitative content analysis is to understand the latent variable and is achieved when the researcher stays close to the data, providing a "rich description" of the participants' experience to further clarify the concept (Neergaard et al., 2009).

\section{Reliability and Validity Versus Trustworthiness}

All participants were provided the opportunity to review the transcript from their interview and allowed to respond in the event the transcript did not accurately portray their thoughts. No participants responded or identified an inaccuracy within their transcript, thus increasing the credibility of the study findings. To ensure dependability, it is believed that data saturation was reached; therefore, should the same study design be replicated, similar results should be found. To increase the confirmability of findings, and since the primary researcher is a neophyte to conducting qualitative research, during the early phase of data analysis, a second researcher experienced with qualitative data analysis reviewed several transcripts to aid in validating the codes developed from the data. Peer debriefing with the primary adviser took place at regular intervals and occasionally with other committee members. Sandelowski (1998) posits that peer debriefing can provide "expert criticism" (p. 470), assist with question revision and framework 
selection, and suggest how data should be represented. To ensure the authenticity of the data analyzed after possible themes were identified, thematic sentences were identified to preserve the intricate nature of each participants' experience with the phenomenon. Transferability is addressed in the limitations section.

\section{Results}

Thirteen nurse educators, representing each of the three academic sites - large urban $(N=$ $6)$, small urban $(N=3)$, northern $(N=4)$-participated in the study. Data analysis highlighted nurse educators' perspectives on ecoliteracy, which are organized according to the following five key themes that are reflective of the interview questions: (a) importance of ecoliteracy in undergraduate nursing programs, (b) current integration of ecoliteracy concepts in curricula, (3) future considerations for ecoliteracy content, (d) barriers to including ecoliteracy content in the curriculum, and (e) Strategies to address barriers.

\section{Importance of Ecoliteracy in Undergraduate Nursing Programs}

Ecoliteracy was "important" or "very important" for nursing student education, according to all the educators interviewed, except for one. Most educators stated that understanding the connection between human health and the environment is important for undergraduate nursing students. Several educators stated nurses have a responsibility to understand their role related to the environment and human health. As one educator explained, this understanding is needed "because nurses work with people within a community that is impacted by ecology."

Being able to identify the reciprocal relationship between health care systems and the ecosystem was reported by some participants as being "very important" to nursing students' education. One participant explains, "[There is] a need to understand the dent in the armour that these huge hospitals put on the environment in terms of things like water and waste disposal, generating impact, in terms of how green is our health care system." Another educator referred to the reciprocal relationship, stating, "The impact... the profession has on the environment and vice versa, the impact the environment has on our profession and our people and our clients, I really see it as something that's fundamental to health." The same individual goes on to say, "There's an understanding among everyone [colleagues] that the environment plays a role [in health]. I don't think it's gotten so far as to understanding that the health of the environment, you know, is reciprocal with our own health."

One nurse educator saw the nursing licensing exam focus on biomedical issues as dictating teaching content. Therefore, as environmental health issues currently are not part of the exam, she did not consider these critical areas for teaching:

The pragmatic question I believe is what the students are focused on. And what nurse educators are obligated to focus on. Whether we like it or not, the focus is on writing a qualifying exam that is based on biomedical issues. Viewed in this sense, it is not considered important.

\section{Current Integration of Ecoliteracy Concepts in Curricula}

The current integration of concepts that support ecoliteracy in the curricula varied significantly, depending on the course. Nurse educators teaching courses addressing prevention of illness or health promotion and/or maternal-child health reported having formal course objectives supporting ecoliteracy. One educator reported, "We did talk about, you know, the shifts in trends 
in health and illness patterns related to climate change and global warming." Another educator described how ecoliteracy is a new concept entering the curriculum recently.

Where I first recognized that - that environment awareness is sort of starting to come into the curriculum — was two years ago when our Maternal Child courses we're teaching, they actually put into the curriculum that we needed to address environment and child health. So they made the formal link, and that was the first time I'd seen it.

Educators whose teaching responsibilities fell outside the courses mentioned above more frequently reported no formal course ecoliteracy objectives. An educator noted the absence of any formal environmental health content: "We don't have a formal course to discuss it. It is one of the concepts that, I think, we informally consider ourselves - we call it threading it - threading it through the curriculum." Another participant explained that ecoliteracy concepts are not embedded in the curriculum. Rather, the content is addressed informally, usually during a discussion related to current events such as climate change.

Classroom and online discussion were the most common forms of ecoliteracy content delivery described by the 13 educators. The educators identified various topics where ecoliteracy content was raised, including discussion about nursing roles and how nurses take action to assess environmental risk. As one educator described, "I would have them (students) read the article in advance, and then I would do a short presentation just on the broader issue of environmental concerns... and then would have a class discussion." Additional forms of content delivery included lecture, group research projects, presentations, use of video clips, and guest speakers.

\section{Future Considerations for Ecoliteracy Content}

All 13 educators interviewed, except one, reported seeing opportunities to expand ecoliteracy concepts in undergraduate nursing theory and clinical courses to build an ecoliterate nursing workforce in the future. Key areas for including ecoliteracy content were in acute/chronic health conditions and older adult and pediatric courses. One educator remarked about the linkage to clinical practice in acute health settings, "There are... things in acute health when it comes to waste. ... It could be part of a clinical thing, too ...the environment or ecoliteracy are part of - you know, hospital-based nursing." This was an interesting finding as Lopez-Medina et al. (2019) identified the growing need for nursing professionals to address sustainability and health care waste, acknowledging that this content is largely missing from nursing curricula. Some educators thought that the content would fit best in more general courses that address chronic care, while others identified a population-specific course. For example, one educator stated, "I am thinking places where this... would fit is we have an entire course that talks about the older adult. Certain groups to me are more susceptible to the impact of the environment." This same participant saw pediatric courses as a potential fit for content supportive of ecoliteracy:

Because children experience the world differently than adults... I'm not really sure how aware people are of it, but there is a lot of literature... that talks about the impact of the environment on... small humans and that children are more susceptible... than adults.

Another educator felt leadership and professional practice courses might be a potential fit for ecoliteracy education:

I would think there would be opportunity to introduce... in professional practice, like the Canadian Nurses Association's Code of Ethics, and how it stresses the need for nurses to take action and to do education about safe environments and protecting the environment. 
Most frequently, the educators reported community-based clinical settings as a potential fit for content that would support ecoliteracy in undergraduate nursing programs. One educator suggested the need for case studies related to environmental health for deep learning: "We could create clinical practice experiences for students that are much more open ended... the best way to understand how important this/it is (environmental health), to actually be put in a situation."

\section{Barriers to the Inclusion of Ecoliteracy Content in Curriculum}

The majority of educators shared a concern about adding new content into the curriculum's heavy load. As one educator stated, "I think that our curriculums aren't introducible to add new material in because it's so jam packed full of material already." Most educators perceived that undergraduate nursing education concentrated on medical or surgical nursing practice, with less focus on public/community health content related to ecosystem health.

The provincial regulatory body for nursing was also identified as a barrier. Educators identified that this regulatory body valued biomedical content: "The reason that's given [from academic leadership] is there's so much pressure from outside [the regulatory body] to increase the medical-surgical content [that] a lot of other things are getting squeezed out." Other educators posited that the issue extends beyond the pressure placed upon academic sites and nursing schools by regulatory bodies.

The attitude among nurse educators, who place a higher value on the medical model or the treatment of illness than the prevention of illness, is also a barrier. Focusing on ecoliteracy is most related to prevention, rather than treatment. As one participant explained, most nursing educators are interested in teaching only the biomedical model of treatment: "Some of us think we need to teach students to place a great emphasis on preventing health problems... Still I would say, you know, $90 \%$ of my colleagues are... interested in students coming out [of our program] so they can treat these people."

Several nurse educators indicated that ecoliteracy content at their academic site is threaded or laddered throughout the nursing program and viewed this as a barrier. As one educator noted, discretionary material, such as ecosystem health, is often lost: "Every course leader or course professor has discretion about, you know, what goes into their course. And I think a lot of the threaded and laddered content gets lost."

\section{Strategies to Address Barriers}

Educators identified strategies originating both within and external to their programs to increase the uptake of ecoliteracy content in undergraduate nursing programs. Internal strategies focused primarily on increasing ecoliteracy knowledge among educators, ranging from conducting formal research projects to having presentations and informal discussions. One educator stated:

Perhaps, there is opportunity in staff meetings and faculty meetings to sort of find out from colleagues and have a discussion about "Well, what are you doing?" or "What should I be doing?" ...encouraging people to do research on ecoliteracy and publishing, sort of educating the educators about what changes need to be made.

Another educator suggested presenting to the faculty curriculum committee on the topic of threading environmental health content as one method for creating curricular change. Although several participants believed that ecoliteracy content would be lost if threaded through the curriculum, others felt that threading and laddering content could be a positive strategy. One person saw the threading of ecoliteracy content as more effective and efficient, rather than teaching 
the content as a stand-alone course. Further, an educator suggested that if environmental health content is threaded within a curriculum, the course objectives must reflect this to ensure that it is not lost.

Educators interviewed frequently mentioned the potential role of provincial professional nursing organizations to address the barriers to the inclusion of environmental health content in the curriculum. In particular, educators believed that environmental health should be part of nurses' entry-level competencies, as determined by the provincial nursing regulatory body. One educator viewed the professional association of registered nurses in the province as the starting point, stating, "If the professional association put forward a powerful argument in favour of this kind of beginning education in... an entry level practice program... the [regulatory body] might be interested in hearing about that."

\section{Variation in Findings Between Academic Sites}

Findings were analyzed to determine commonalities or differences of perceptions between nurse educators in different study sites. Consistent across study sites was the agreement (except for one educator from the large urban site) that ecoliteracy in pre-licensure nursing education was important or very important.

Variation between sites was noted regarding environmental health content in the institution. For example, educators from the small urban and northern study sites were more likely to indicate being unaware of formal course objectives supporting ecoliteracy than participants from the large urban study site. Educators from the northern study site reported a lack of formal curriculum that would support ecoliteracy in their program. One educator suggested that the problem went beyond their own program: "I think that, probably, it [ecoliteracy] isn't directly addressed very well... in education and nursing, at... this point." Nurse educators from the small urban and northern sites reported having flexibility in choosing topics for assignments, which allowed for the inclusion of ecoliteracy topics. One participant believed that in addition to one's personal interests, having knowledge of community needs and having smaller class sizes (which were more common in the small urban and northern sites) likely contributed to the ability to complete ecoliteracy projects when it aligned with the course syllabus.

\section{Discussion}

This study of undergraduate nursing education explored nurse educators' perceptions of environmental health content in one Canadian province. The educators in this study reported that ecoliteracy is of high importance for nursing students and the profession of nursing. This belief is in line with the CNA (2017a) Nurses and Environmental Health position statement, which states, "There is a role for every nurse to promote and support actions to optimize the health of the environment because of the link to human health" (p. 1). The study findings also support the conclusion that ecoliteracy content is insufficiently addressed in undergraduate nursing programs (Leffers \& Butterfield, 2018; Leffers et al., 2017; Nicholas \& Breakey, 2017). Consistent with Nicholas and Breakey (2017), this study identified the need to encourage greater faculty involvement in teaching ecoliteracy content.

Participants felt ecoliteracy was important for nursing students because of the connection between human health and the environment, as well as the health care system's impact on the surrounding ecosystem. This finding is consistent with the CNA (2017a) Nurses and Environmental Health position statement, which recognizes the relationship between the health 
system and the surrounding environment. The position statement posits that as nurses become ecoliterate and recognize the impact of the health system on the environment, their professional and personal practice will encourage environmental health and sustainability.

The courses identified as being a good fit for environmental health content include nursing issues, health assessment, fundamentals of nursing, community health, maternal-child health, older adults, and policy or leadership courses. These courses for ecoliteracy content are consistent with those reported in the literature (Gerber \& McGuire, 2010; Leffers et al., 2017). Some clinical settings' opportunities were also noted, which supports Jackman-Murphy's (2015) focus on the inclusion of environmental health content in the clinical practice setting. Consistent with Nicholas and Breakey (2017), Leffers et al. (2017), and Lilienfeld et al. (2018), our study found that more ecoliteracy education is needed to increase the nursing profession's role in environmental health.

One contradiction apparent in our study was that some educators felt environmental health content should be threaded throughout a nursing program curriculum. In contrast, other educators felt a stand-alone course or continuing education would be a better fit. The literature includes various methods that would support the inclusion of increased environmental health content in prelicensure nursing programs. Leffers et al. (2017) posited that environmental health content should be incorporated into existing nursing courses and at all levels of nursing education (pre-licensure, graduate, and continuing education).

\section{Implications for Nursing Education}

Despite the professional expectation that graduates of pre-licensure nursing programs have a strong foundation in ecoliteracy, environmental health content in pre-licensure nursing programs varies because of a variety of barriers. Nurses require more environmental health content, which could be achieved by (a) threading environmental health content throughout the undergraduate curriculum and (b) developing a continuing education course.

\section{Threading Ecoliteracy Content in Curriculum}

Content saturation was the most prominent barrier identified, which indicates that nursing programs have an overloaded curriculum. However, despite this barrier, nursing educators should move forward to develop learning objectives and integrate environmental health content into the nursing curriculum. To purposefully include environmental health content within undergraduate nursing programs, our findings suggest that academic sites include formal learning objectives within relevant courses (Leffers et al., 2017).

\section{Developing a Continuing Education Course}

With the growing concern related to environmental health and ecological health, nurses and the health care profession as a whole must include climate content as an integral part of their education (Lilienfeld et al., 2018). Continuing education for registered nurses (RNs) is one way to address the current knowledge gap within the profession. A continuing education course or postgraduate course can be developed and offered as an elective or to RNs as part of their continuing competency (Leffers et al., 2017).

\section{Limitations}

The primary limitation is that the number of participants $(n=13)$ in this study was lower than anticipated. Although data saturation was reached, the possibility that not all perspectives were captured does exist. For example, more participants from the small urban and northern sites 
may have provided further information about the unique ecological health issues impacting those regions and the importance of increasing ecoliteracy content in their programs. A potential explanation for the lower than expected number of participants was identified during the interviews, with some participants reporting confusion regarding the term ecoliteracy. Educators did not always immediately connect it with environmental health, although this connection was provided during the interview. Although the letter of invitation included a description of the concept of ecoliteracy, nurse educators may have hesitated because of a lack of expertise in this area. Similarly, Leffers et al. (2017) and Sullivan-Marx and McCauley (2017) recognized the deficit in nursing faculty knowledge in relation to climate change content and the barriers to its inclusion into nursing programs. An additional limitation is that the study was conducted only with nurse educators in one Canadian province, so the findings may not be applicable to nurse educators in other geographic locations.

\section{Recommendations for Future Research}

To fully illuminate the gap in knowledge about educators' perspectives on ecoliteracy in Canadian undergraduate nursing education, further research, such as a pan-Canadian scoping review to scan nursing programs or an online survey of nurse educators, is required to obtain the views of educators in other jurisdictions in Canada. The ecological planetary health model (Leffers et al., 2017) has been suggested as a potential framework to integrate climate change curricula into nursing education and could be an interesting model to guide future research. The model takes into consideration the nursing implications that apply at various levels-individual, family, community, regional, international, planetary - and strategies that relate to climate change, adaptation, mitigation, and resiliency are listed. Taking the generally accepted nursing metaparadigm and historical conceptualizations of the environment, the goal would be to expand nurses' understanding to consider how their nursing practice impacts the environment and to understand climate change as a public health issue (Kalogirou et al., 2020)

Research is needed to delineate the requisite environmental health knowledge of an entryto-practice RN from that of an advanced practice RN (Leffers et al., 2017). While the reference to environmentally responsible practice in current Canadian entry-to-practice competencies and standards of practice is a starting point, a more comprehensive set of competencies/standards of practice is required to meet the growing need of nurses to participate in mitigation and adaptation efforts. Nursing research can inform the development of competencies and identify where in an undergraduate nursing curriculum environmental health content would be a "good fit" (Leffers et al., 2017). In addition, an exploration of the perspectives of nursing students in (or recent graduates of) pre-licensure education programs on the extent to which their program helped to increase their ecoliteracy would be valuable.

\section{Conclusion}

The professional expectation is that Canada's nursing workforce should be ecoliterate and support environmentally responsible practice. This study suggests that nurse educators agree with this goal but must overcome barriers to teach environmental health. Further research should be conducted to explore how to best achieve ecoliteracy within undergraduate nursing programs in Canada (and elsewhere), including how to differentiate the knowledge required of an entry-topractice nurse and a nurse in a specialty practice area.

The demand for nurses to be literate regarding the natural environment increases as the stability of ecosystems continues to decline, affecting human health and the health care system 
(Leffers et al., 2017). Nursing education needs to adapt and mitigate climate-related human health concerns and develop resilient health care systems and healthy populations. Pre-licensure nursing education programs need to prepare their graduates to fulfill this important role.

\section{Acknowledgement}

This paper is dedicated to the memory of our dear colleague and co-author Dr. Benita Cohen. 


\section{References}

Canadian Association of Schools of Nursing. (2021). Empowering the next generation of health care professionals with knowledge, skills, and supports to address infectious diseases related to climate change in Canada. https://www.casn.ca/2018/10/projectannouncement-empowering-the-next-generation-of-health-care-professionals-withknowledge-skills-tools-and-supports-to-address-infectious-diseases-related-to-climatechange-in-canad/

Canadian Federation of Nurses Unions. (2019). Climate change and health. https://nursesunions.ca/wp-content/uploads/2019/05/CFNU_climatechange-web.pdf

Canadian Nurses Association. (2017a). Nurses and environmental health. https://hl-prod-ca-ocdownload.s3-ca-central-1.amazonaws.com/CNA/2f975e7e-4a40-45ca-863c5ebf0a138d5e/UploadedImages/documents/Nurses_and_environmental_health_position statement.pdf

Canadian Nurses Association. (2017b). Code of ethics for registered nurses. https://hl-prod-caoc-download.s3-ca-central-1.amazonaws.com/CNA/2f975e7e-4a40-45ca-863c5ebf0a138d5e/UploadedImages/documents/Code_of_Ethics_2017_Edition_Secure_Inter active.pdf

Canadian Nurses Association. (2017c). Climate change and health. https://hl-prod-ca-ocdownload.s3-ca-central-1.amazonaws.com/CNA/2f975e7e-4a40-45ca-863c5ebf0a138d5e/UploadedImages/documents/Climate_change_and_health_position_statem ent.pdf

Canadian Public Health Association. (2019). Climate change and public health. https://www.cpha.ca/sites/default/files/uploads/policy/positionstatements/climatechangepositionstatement-e.pdf

College and Association of Registered Nurses of Alberta. (2019). Entry-level competencies for the practice of registered nurses. https://nurses.ab.ca/media/5ndpyfar/entry-levelcompetencies-for-the-practice-of-registered-nurses-mar-2019.pdf

College of Nurses of Ontario. (2020). Entry-to-practice competencies for registered nurses. http://www.cno.org/globalassets/docs/reg/41037-entry-to-practice-competencies-2020.pdf

College of Registered Nurses of Manitoba. (2019). Entry-level competencies for the practice of registered nurses. https://www.crnm.mb.ca/uploads/document/document file 92.pdf

Community Health Nurses of Canada. (2019). 2019 Canadian community health nursing professional practice model \& standards of practice. https://www.chnc.ca/en/standardsof-practice

Gerber, D. E., \& McGuire, S. L. (2010). Teaching students about nursing and the environment: Part 1-Nursing role and basic curricula. Journal of Community Health Nursing, 16(2), 69-79. https://doi.org/10.1207/s15327655jchn1602_1

Goleman, D., Bennett, L., \& Barlow, Z. (2012). Ecoliterate; How educators are cultivating emotional, social and ecological intelligence. Jossey-Bass 
Graneheim, U., \& Lundman, B. (2004). Qualitative content analysis in nursing research: concepts, procedures and measures to achieve trustworthiness. Nurse Education Today, 24(2), 105-112. https://doi.org/10.1016/j.nedt.2003.10.001

Iira, T., Ruth, M., Hannele, T., Jouni, J., \& Lauri, K. (2020). Finnish nurses' perceptions of the health impacts of climate change and their preparation to address those impacts. Nursing Forum, 56(2), 365-371. https://doi.org/10.1111/nuf.12540

International Council of Nurses. (2018). Nurses, climate change and health. https://www.icn.ch/sites/default/files/inlinefiles/ICN $\% 20 \mathrm{PS} \% 20$ Nurses $\% 252 \mathrm{c} \% 20$ climate $\% 20$ change $\% 20$ and $\% 20$ health $\% 20 \mathrm{FINAL}$ $\% 20 . p d f$

Jackman-Murphy, K. (2015). Environmental health 101: Incorporating environmental health into the nursing curriculum. Teaching and Learning in Nursing, 10(4), 192-195. https://doi.org/10.1016/j.teln.2015.05.005

Kalogirou, M. R., Olson, J., \& Davidson, S. (2020). Nursing's metaparadigm, climate change and planetary health. Nursing Inquiry, 27(3), e12356. https://doi.org/10.1111/nin.12356

Kim, H., Sefcik, J. S., \& Bradway, C. (2017). Characteristics of qualitative descriptive studies: A systematic review. Research in Nursing \& Health, 40(1), 23-42. https://doiorg.athena.rrc.mb.ca:2047/10.1002/nur.21768

Landrigan, P. J., Fuller, R., Acosta, N. J. R., Adeyi, O., Arnold, R., Basu, N., Bald'e, A. B., Bertollini, R., Bose-O’Reilly, S., Boufford, J. I., Breysse, P. N., Chiles, T., Mahidol, C., Coll-Seck, A. M., Cropper, M. L., Fobil, J., Fuster, V., Greenstone, M., Haines, A., ... Zhong, M. (2018). The Lancet Commission on pollution and health. The Lancet, 391(10119), 462-512. https://doi.org/10.1016/S0140-6736(17)32345-0

Leffers, J., \& Butterfield, P. (2018). Nurses play essential roles in reducing health problems due to climate change. Nursing Outlook, 66(2), 210-213. https://doi.org/10.1016/j.outlook.2018.02.008

Leffers, J., Levy, R., Nicholas, P., \& Sweeney, C. (2017). Mandate for the nursing profession to address climate change through nursing education. Journal of Nursing Scholarship, 49(6), 679-687. https://doi.org/10.1111/jnu.12331

Lilienfeld, E., Nicholas, P., Breakey, S., \& Corless, I. (2018). Addressing climate change through a nursing lens within the framework of the United Nations Sustainable Development Goals. Nursing Outlook, 66(5), 482-494. https://doi.org/10.1016/j.outlook.2018.06.010

Lopez-Medina, I., Álvarez-Nieto, C., Grose, J., Elsbernd, A., Huss, N., Huynen, M., \& Richardson, J. (2019). Competencies on environmental health and pedagogical approaches in the nursing curriculum: A systematic review of the literature. Nurse Education in Practice, 37, 1-8. https://doi.org/10.1016/j.nepr.2019.04.004

Neergaard, M. A., Olsen, F., Anderson, R. S., \& Sondergaard, J. (2009). Qualitative description the poor cousin of health research? BMC Medical Research Methodology, 9(52), https://doi.org/10.1186/1471-2288-9-52 
Nicholas, P. K., \& Breakey, S. (2017). Climate change, climate justice, and environmental health: Implications for the nursing profession. Journal of Nursing Scholarship, 49(6), 606-616. https://doi.org/10.1111/jnu.12326

Polit, D., \& Beck, C. (2020). Nursing research: Generating and assessing evidence for nursing practice (11th ed.). Wolters Kluwer.

Sandelowski, M. (1998). The call to experts in qualitative research. Research in Nursing \& Health, 21(5), 467-471. https://doi.org/10.1002/(sici)1098-240x(199810)21:5<467::aidnur9>3.0.co;2-1

Sandelowski, M. (2000). Whatever happened to qualitative description? Research in Nursing \& Health, 23(4), 334-340.https://doi.org/10.1002/1098-240x(200008)23:4<334::aidnur9>3.0.co;2-g

Sandelowski, M., \& Leeman, J. (2012). Writing usable qualitative health research findings. Qualitative Health Research, 22(10), 1404-1413. https://doi.org/10.1177/1049732312450368

Setti, L., Passarini, F., De Gennaro, G., Barbieri, P., Licen, S., Perrone, M. G., Piazzalunga, A., Borelli, M., Palmisani, J., Di Gilio, A., Rizzo, E., Colao, A., Piscitelli, P., \& Miani, A. (2020). Potential role of particulate matter in the spreading of COVID-19 in Northern Italy: first observational study based on initial epidemic diffusion. BMJ Open, 10(9), e039338. https://doi.org/10.1136/bmjopen-2020-039338

Sullivan-Marx, E., \& McCauley, L. (2017). Climate change, global health, and nursing scholarship. Journal of Nursing Scholarship, 49(6), 593-595. https://doi.org/10.1111/jnu.12342

Watts, N., Amann, M., Ayeb-Karlsson, S., Belesova, K., Bouley, T., Boykoff, M., Byass, P., Cai, W., Campbell-Lendrum, D., Chambers, J., Cox, P. M., Daly, M., Dasandi, N., Davies, M., Depledge, M., Depoux, A., Dominguez-Salas, P., Drummond, P., Ekins, P., ... Ghanei, M. (2018). The Lancet Countdown on health and climate change: from 25 years of inaction to a global transformation for public health. The Lancet (London, England), 391(10120), 581-630. https://doi.org/10.1016/S0140-6736(17)32464-9 